\title{
MEASUREMENT OF THE HUMAN POTENTIAL BY MEANS OF THE INTERNAL ENTROPY IN THE FIRM
}

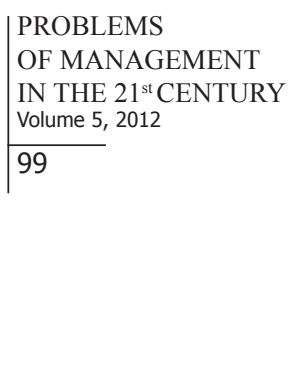

Jana PIchová

Slovak university of Technology in Bratislava, Slovak Republic

E-mail: jana.plchova@stuba.sk

\begin{abstract}
The approach expressed by its author A. Kopčaj as a Spiral management is based on the philosophy according to which the firm is perceived as a living organism. Living organisms are guided by the principle of reducing their entropy in order to ensure the inevitable energy as well as their long-term survival. The contribution is analysing one of the potential applications of the above-indicated approach to the firm in which the measurement of the so-called internal entropy gives the possibility to determine in a very precise way whether the new managerial approach can be or cannot be implemented in the firm in the current state or whether it is possible to define the strategies for cultivation of the firm's social capital. The paper proceeds from the data acquired during practical applications of the Spiral management in the environment of the Czech and Slovak companies.
\end{abstract}

Key words: entropy, social subsystem of the firm, technical subsystem of the firm, the Spiral management.

\section{Introduction}

Management theory and practice has been dealing intensively with the research of new more efficient management methods for several years. A lot of new methods were applied successfully in multiple firms, but there is still number of firms which tried a few new methods to modernize management system and often incurred considerable finances, as well as considerable energy of their employees, and yet the implementation of these did not bring the promised results. And if the firm experienced the similar problem several times, the confidence in any new approaches dives and on the contrary there grows the belief that similar ideas may work in Japan or America, but not under "our specific conditions." It results in disillusion and demotivation of employees and management and the worst thing is that the aversion to any changes deepens.

What causes such a chasm in management methods effectiveness in different firms? Is it ever possible to predict which of the provided management methods will be suitable for the firm and which will not work in a given firm? The answer is - it is possible and can be detected by means of the measurement of the state of social capital in the firm and the firm's culture. (Špirko, 2008)

\section{Background to the Problem}

The present article discusses some aspects of using of new genuine management approach which Andrej Kopčaj, its author, named a Spiral management.

The Spiral management is, like the multiple new management approaches, based on 
PROBLEMS

OF MANAGEMENT

IN THE $21^{\text {st }}$ CENTURY

Volume 5, 2012

100

the philosophy of the comprehension of a firm as the living organism. However, the Spiral management is unique in some aspects and certainly worth attention not only in Slovak and Czech entrepreneurial environment. That is to say, it enables to quantify the firm results not only in the field of knowledge and technologies, but also in human capital management, which has not been quantified, yet.

Andrej Kopčaj takes for his starting point the presumption that the enterprise consists of the two subsystems: a technical subsystem, a non-living system which follows the principles of equilibrium thermodynamics and a social subsystem. The management of social system must be based on the dynamics of systems which interact with environment, i.e. disequilibrium thermodynamics, which has often been omitted up to now.

Technical subsystem of the firm consists of all materialized and non-materialized knowledge and processes of the firm. The following seven basic macro processes can be identified in every firm:

- Research and development,

- Economics and finance

- Purchase and storage,

- Manufacturing and maintenance,

- Logistics and informatics,

- Administration and personnel management,

- Marketing a sale of products.

Any enterprise must master basic macro processes regardless the field it carries business in.

According to the system approach every process functions as the part of the system, i.e. complexly. That means that with its functionality it enables also the functioning of all the other processes at the same time.

Technical subsystem of the firm is a system which follows thermodynamic principles. The following principles are valid for any closed, non-living system:

1. The energy of its internal environment is constant,

2. The entropy of its internal environment only grows,

3. The limit of its state is a probability of entropic 1 - so any non-living system moves towards its extinction.

Therefore according to the thermodynamic principles every component of technical subsystem senesces in time - i.e. its entropy increases by the influence of physical depreciation or the changes in entrepreneurial environment. The state of malfunction or complete physical or external depreciation, when the system entropy is equal to 1 , is the limit state for all the components of technical subsystem.

Social subsystem brings the energy of people into the processes going on in a firm. It is the very human potential that becomes the most important competitive advantage in the firms with modern management. A social subsystem is living, open system which follows Prigogine's principles, not the thermodynamic principles. Just the implementation of Prigogine's principles may be considered the highly unique approach to management, which certainly deserves attention.

The laws valid for the living, open system were defined by Ilya Prigogine, the Belgian physicist and chemist of Russian origin who won Nobel Prize for chemistry in 1977 just for the development of thermodynamics of disequilibrium, irreversible systems.

Prigogine defined the basic law of living systems behaviour: "The living - open systems get more and more energy for their existence which causes the fact that they must evict more and more entropy into the environment. The growth of entropy in the environment makes them to increase the degree of their complexity which consequently enables them to get more energy from their environment, etc." 
According to I. Prigogine, the condition of the existence of living, open system is the capability to:

1. Get the energy from the external environment,

2. Evict the energy to the external environment,

3. Increase its degree of complexity in critical growth of entropy, i.e. develops itself.

\section{Entropy From the management Perspective}

Whether we manage technical or social system of enterprise, in both cases we encounter the term entropy which is a key term for the management of enterprise based on the principles of laws of nature. The term entropy in thermodynamics represents the degree of disordering of physical system. However, this meaning of entropy has not been used for a long time just in physical chemistry or mathematics, but it became known in biology, sociology and most recently in management, as well. (Bondareva, 2009)

According to the second sentence of thermodynamics the entropy of physical system only grows in time. At the same time the entropy is a degree of capability or admissibility of systems to perform work with energy. In the closed system the growth of energy is accompanied by decreasing of energy capable to perform work. So, the higher entropy is in the system, the less this system is capable to perform work. (Kopčaj, 1997)

\section{External Entropy}

It has been proved that in practice it is possible to detect the level of functioning of the individual macro processes, which form the part of technical subsystem of enterprise just by the means of the degree of their malfunction, i.e. according to the amount of entropy in the system. In Spiral management this value is called the external disordering of the system and it is known as the external entropy.

\section{Internal Entropy}

It is more demanding to understand the detecting of social subsystem malfunction. According to the second Prigogine's law, the capability of elimination of entropy by its evicting into the external environment is the condition of living systems existence. But what do we understand under the term entropy when considering the social subsystem in the firm, i.e. the employees? Every man, an employee of the firm disposes of certain amount of life energy. But of course, people are not always capable and willing to provide all this energy to the firm. It may be proved that every living system may be in one of five energizing states. So according to this principle the employees of the firm may be in one of these energetic states:

I. Co-adventurer - is the highest possible level of involvement of the employee with the full inner and motivational responsibility for the success of the firm. In this energetic state the employee sets the most demanding level of commands and prohibitions himself, uses the opportunities for the benefit of the firm in creative way and the most essential thing is that he/she changes the risks into the opportunities.

II. Innovator not only fulfils the commands and prohibitions, but uses the opportunities for the benefit of the firm in creative way and minimizes problems and risks, as well.

III. Executor fulfils unambiguous commands and prohibitions. But he/she requires the chief to help him/her to overcome more complicated problems.

IV. Semi-executor fulfils unambiguous commands and prohibitions under the enforcement and pressure whereby he/she grabs the possible opportunities for himself and transfers the risks to the organization. 
PROBLEMS

OF MANAGEMENT

IN THE $21^{\text {st }}$ CENTURY

Volume 5, 2012

102

V.Egocentric employee knowingly violates even unambiguous instructions, commands and prohibitions to maximize his/her own benefit on the expense of organization. This energetic state is the most malignant for the organization and the organization pays its destructor. (Kopčaj, 2007)

It is important for the organization to know how many its employees are in given time in the required and/or undesired state and for how long. Nevertheless, the result of the measurement does not tell about the character or structure of personality of organization employees. But the results of the measurements show the evidence of the efficiency of cultivating strategies in the firm, i.e. the strategies which reduce the ratio of undesired behaviour and increase the ratio of desired state of employees. The same person in the declining enterprise culture will occur more often in undesired energetic state than the same person in the enterprise with highly cultivated social capital.

The starting point for the measurement of firm successfulness is the calculation of HHR (Human Resources Ratio), i.e. the ratio of people considered to be the source of successfulness. (Kopčaj, 1999)

$$
\text { HRR }=\frac{\text { I. }+ \text { II. }}{\text { IV. }+ \text { V. }}
$$

HRR indicator shows the ratio of employees who are engaged in the firm as the source (state I and II) to the employees who are in the state which decelerates the firm (IV and V). If this indicator is lower than 1, the firm does not behave as the living organism, but mechanical machine, i.e. the people just perform the commands. In such a firm it is not possible to expect any synergic effects and any methods assuming involvement and creativity on the side of the employees fail.

This indicator clearly informs about the firm culture level in given organization.

By means of the measurement of the ratio of firm employees in the individual energetic states it is possible to express the amount of entropy in social subsystem of the firm, as well - i.e. so called internal entropy.

\section{Energizing Strategies}

To cultivate five possible energizing states of employees, the spiral management utilizes and defines three energizing strategies (ES):

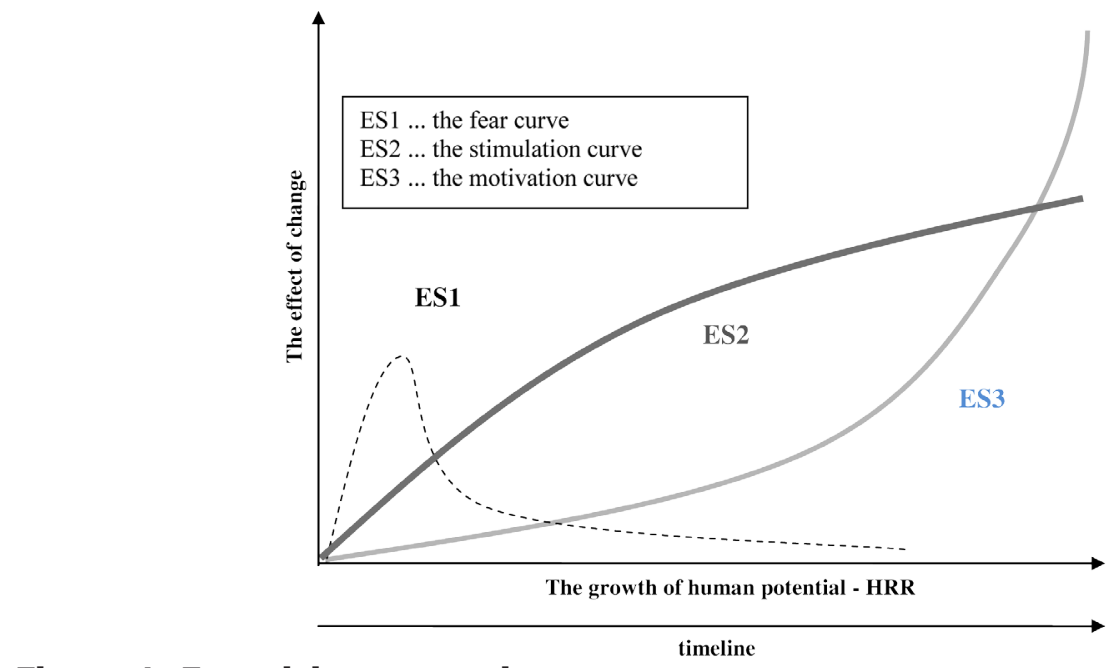

Figure 1: Energizing strategies. 
ES1 - removal, displacement and the purification of the system from entropy (ES1 curve shows the course and efficiency of this strategy. It is also called the fear curve.)

ES2 - stimulative merit pay for the fulfilment and adherence of orders and prohibitions creating successful product or the creation and implementation of new ideas (ES2 curve shows the course and efficiency of the strategy. It is also called the stimulation curve)

ES3 - motivating status valuation for the growth of potential of successfulness (ES3 curve shows the course and efficiency of the strategy. It is also called the motivation curve).

\section{The Researcher's Role}

The authoress of this research took part personally in the measurements in multiple enterprises in Slovak and Czech Republic as the observer and later as fellow worker and had the possibility to consult the results of measurements connected with the diagnostics of the states of the firms. She had the possibility to consult the setting of suitable methods and tools for given firm level with A. Kopčaj, the author of the method and his team. She could discuss such an innovative approach to the management with the employees of given firms, as well. She uses the results of her research especially in her pedagogic practice to inform the students about new approaches to the enterprise management and change management.

\section{Theoretical Perspective}

If we transform the basic issue of management "What is necessary to do to be better in future? into the form "For which partial objectives are we willing to invest our time and life energy?

Just three basic wealth components should be the answer:

- Assurance of existence = economic successfulness ES (profitability)

- Quality of existence = potential of successfulness PS (competitiveness)

- Length of existence $=$ time successfulness TS (long-term existence)

From the perspective of laws of living systems behaviour defined by I. Prigogine it means

- Getting the energy (matter, information) from external environment

- Evicting the energy from internal and consequently from near external environment

- Increasing of complexity to accelerate change cycles and extent the length of existence.

These three basic objectives can be shown graphically in the form of triangle in which each one of the objectives is placed in one corner of the triangle. It is called a Kopčaj's management triangle according to its author. It is an isosceles triangle with the ratio of the length of legs to baseline in the ratio of golden section (i.e. 1,618) which creates the optimal parameters for the spiral dynamics of wealth growth (the name Spiral management is derived from that) (Kopčaj, 2007). 
PROBLEMS

OF MANAGEMENT

IN THE $21^{\text {st }}$ CENTURY

volume 5, 2012

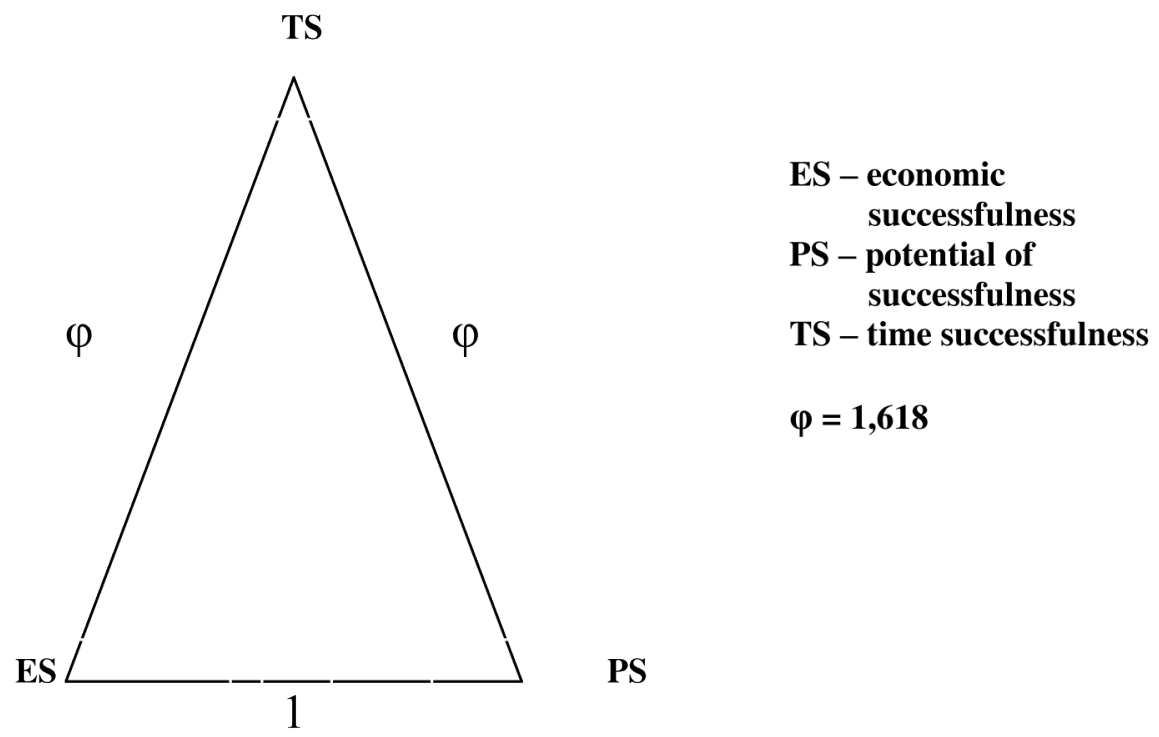

Figure 2: Kopčaj's management triangle.

"To bestir" the management triangle so as to create the dynamics of the spiral growth of wealth we must know the laws of three corners and three triangle's connecting lines and mainly use them in the management of the fir. It can be proven that the local reduction of entropy is always the driving core of the spiral growth of wealth. (Kopčaj, 2007)

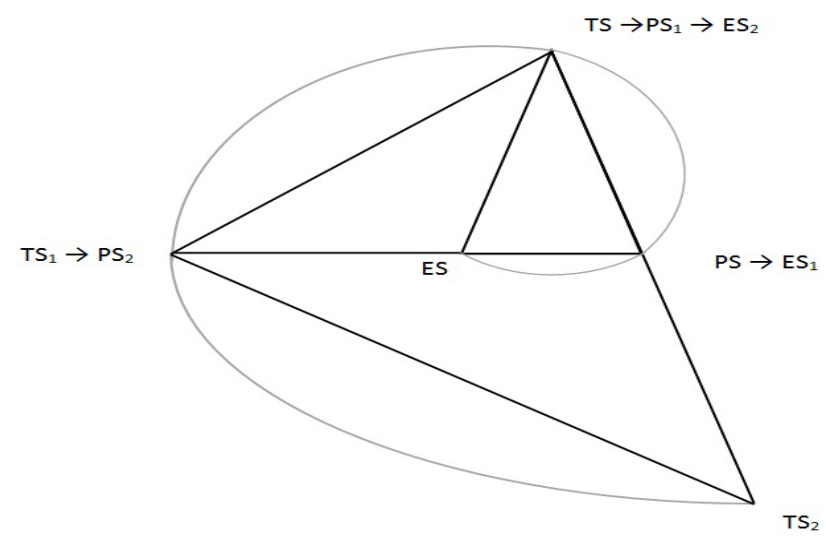

Figure 3: Rotation and growth of golden triangle.

So the firm which follows the laws of nature reduces its entropy (both internal and external) and it reaches the other two objectives - the long-term and financially successful existence as the result of such management.

\section{Methodology of Research}

All the measurements necessary for the diagnostics of the firm are performed in practice in representatively selected sample of employees of given firm, i.e. 25-30 people. The group consists of top level managers, medium level managers and workers. The measurement is performed by sensational, subjective method. It lasts several days. During the measurement 
the participants of measurement unify their glossary, perception and comprehension of the individual terms and parameters and these activities form the substantial part of measurement

duration. The measured results are subsequently processed by the methods of statistical evaluation of results. The results of the measurement of external, internal and overall entropy, HRR, as well as other parameters are repeatable and sufficiently accurate as the starting point for the diagnostics of the state and subsequent management of the firm.

\section{Ethical Considerations}

The ethical consequences of the management of managers which is based on the principles of Spiral management are interesting especially for the reason that unlike the classic management they do not define the making of gains as the primary objective of the firm. The basic objective of the firm in the management according to the principles of Spiral management is increasing of its own potential of successfulness by means of reducing the level of internal and external entropy in the firm. As it has been already mentioned the firm managed in this way gain the profit, but it is the result of its high competitiveness. The objectives of business set in this way ensure at the same time that the enterprise is not inferior to short-term endeavours after maximization of profit at the expense of the damage of environment, their own employees or customers which are often common in firms whose business philosophy is based on just "classic" approach.

\section{Data Analysis}

The table shows the average measured values of the energizing of the employees in the analyzed firms in SR.

Table 1. Energizing of the employees in Slovakia.

\begin{tabular}{|c|c|c|c|c|c|}
\hline $\begin{array}{c}\text { The state of ener- } \\
\text { gizing }\end{array}$ & Co -adventured & Innovator & Executor & Semi -executor & Egocentric \\
\hline $\begin{array}{c}\text { The average values } \\
\text { in Slovakia }\end{array}$ & $7 \%$ & $16 \%$ & $44 \%$ & $25 \%$ & $8 \%$ \\
\hline HRR $=\frac{\text { I. }+ \text { II. }}{\text { IV. }+ \text { V. }}$ & \multicolumn{2}{|l}{0.7} & \\
\end{tabular}

According to actual measurements the average HRR value of Czech and Slovak firms is approximately 0.7 .

\section{Results of Research}

In such results it is clear that people in such a firm can be managed just with methods based on unambiguous setting of rules, commands and prohibitions and rigorous control of their compliance. If the firm is not prepared for the acceptation of specialized management methods and tools, it is useless to introduce them. Only in HRR values higher than 1 we talk 
PROBLEMS

OF MANAGEMENT

IN THE $21^{\text {st }}$ CENTURY

Volume 5, 2012

106

about biologisation of enterprise. The employees in these firms involve themselves in work, create ideas and the synergic effect can be observed here. This is the reason why almost all the firms in Slovak Republic prefer the conception according to ISO 9001 in introducing quality management systems, while only several firms in Slovak Republic apply TQM conception which assumes high involvement of employees.

Based on long-term observations it also may be stated that the firms which reached HRR value higher than $1.5 \mathrm{did}$ not have economic problems. On the other hand the firms whose measured HRR value was lower than 0.5 were on the edge of economic collapse.

\section{Discussion}

The aim of this article is to report on a new approach to management which is still known only by Slovak and Czech Republic. Spiral management is not only a new method of management, but principally new view of firm management. This approach differs from the other ones mainly in the fact that the enterprise is investigated and managed as the system which consists of non-living and living part which follows the different laws of nature.

The possibility to set the value of malfunction of both enterprise subsystems, i.e. determine the value of external and internal entropy of the firm brings a completely new view of the management and opens unsuspected possibilities. From the viewpoint of application of new management methods this approach is then usable in the determination to which degree is enterprise culture cultivated in firm and so to which degree the employees identify with the objectives of whole organization. If the new management techniques and methods which require motivated people are applied in the firm with high value of internal entropy, they never can bring promised effects and will not work. So the approach of Spiral management enables to diagnose the state of firm and on the base of it to suggest the most suitable methods or techniques of management determined for given initial level of firm.

\section{Conclusions and Implications}

The spiral management is a diametrically new approach to the management in our situation which is based on the respecting of the laws of nature accompanying the spontaneous growth of living and non-living systems. These laws are described and explored by natural science. The spiral management may be also perceived as the next stage of natural development of the field of management which deals with the management of firms or organizations. However, the management based on the principles of laws of nature has always existed regardless the fact whether we realize it or not. This fact is nowadays supported by achieved scientific knowledge in this area. From this perspective, the spiral management may be also perceived as the theory based on science because it includes the results of scientific knowledge of various kinds of natural science and it includes the field of management in scientific sphere.

The objective of the present article is to direct the attention of scientific and expert public also beyond the territory SR and $\breve{C R}$ towards the existence of this new, interesting and successfully implemented approach to the management of firms.

In this article the authoress deals with only one of the interesting contributions of this approach to the management - the possibility to quantify the mass and highness of social capital in the firm and the utilization of this information in the management of the firm.

However, the spiral management provides well-rounded philosophy and the instructions for successful management of firm and people which are based on the awareness of never ending development of the knowledge of the laws of nature and society and their application in the practice of the development of the firm. 


\section{Acknowledgment}

The contribution is a partial presentation of the results obtained from the solution of the research project VEGA No. 1/0713/11 entitled "The professional, social and environmental responsibility of the technologist and manager in conditions of the global economic and ecological crisis" which is solved by the Department of Management of Chemical and Food Technologies, Institute of Management of the Slovak University of Technology.

\section{References}

Bondareva, I. (2009). Finančná podniková subkultúra ako dôležitý prvok formovania finančnej stratégie podniku. [Financial corporate subculture as the important element of creation of financial strategy of enterprise] In: MANEKO, 2 (1), 118-125.

Drucker, P.F. (2009). The effective executive. London: Harper and Row.

Drucker, P.F. (2007). Innovation and enterpreneuership. London: Butterworth-Heinemann.

Drucker, P. (2004). Výzva managementu pro 21. století. Praha: Management Press.

Kopčaj, A. (2010). 7 kroků k výjimečnosti. [Seven steps to excellence]. In: Management a komplexita. CPIT-TU Ostrava.

Kopčaj, A. (2007). Spirálový management. [The Spiral management].Praha: Alfa Publishing.

Kopčaj, A. (1999). Řizení proudu změn. [Management of flow of changes]. Praha: Grada Publishing.

Kopčaj, A. (1997). Košatěni bohatství. [Growth of wealth]. Ostrava: Silma '90.

Krempaský, J. (2012). Podnik vo fluktuujúcom prostredí. [Enterprise in fluctuating environment]. In: Management a komplexita. CPIT -TU Ostrava.

Krempaský, J. (2010). Samovývoj a manažment. [Self development and management]. In: Management a komplexita. CPIT -TU Ostrava.

Plchová, J. (2009). Meranie entropie vo firme ako východisko pre diagnostiku jej stavu. [Measurement of entropy in the company as a basis for diagnosis of its condition]. In: Forum Statisticum Slovacum 4(5).

Špirko, D. (2008). Spoločensko-etický rozmer inžinierskych a manažérskych činností. [Social and ethic dimension of engineering and managerial activities]. In: Proceedings of International Conference "Ekonomické znalosti pro tržní praxi.“" Olomouc, 580-589.

Advised by Irina Bondareva, Slovak University of Technology in Bratislava, Slovakia

Received: October 04, 2012

Accepted: November 22, 2012 